Print ISSN: 2093-9582, Online ISSN 2508-4593

http://dx.doi.org/10.21871/KJFM.2020.3.11.1.19

\title{
The Effects of Customer Quality Assessment on Satisfaction, Self-efficacy, and Loyalty in Franchised Coffee Shops
}

\author{
Soo-Jin CHOI*
}

Received: November 20, 2019 Revised: December 02, 2020 Accepted: December 05, 2020.

\begin{abstract}
Purpose - To understand the assessment basis of customers' coffee shop experience and give more practical advices to the franchised coffee shops which are poorly managed in the competitive market, this study identified factors to measure the quality of customer experience and explored the relationship between these factors and customer satisfaction and loyalty. Further, this study analyzed which role self-efficacy played in the structural relationship between the quality assessment factors, satisfaction and loyalty of franchised coffee shops. Research design, data, methodology - The data were collected from respondents who had visited franchised coffee shops within the previous month through online survey. The questionnaires were surveyed from February 11 to February 14, 2019. A total of 318 responses were collected after excluding four of incomplete or uncandid responses. A structural equation modeling approach was used to examine the proposed hypothesis and a confirmatory factor analysis was employed to verify the four dimensions of quality assessment. Results - The findings of this study are as follows. First, the three of quality assessment variables significantly influenced on satisfaction except environmental quality. Second, economic and service quality significantly influenced on self-efficacy but environmental and menu quality didn't. Third, satisfaction significantly influenced on loyalty but not on self-efficacy. Fourth, self-efficacy significantly influenced on Loyalty. Conclusions - This study identified the four dimensions to assess the franchised coffee shop service - menu, environment, service and economic quality and verified these four dimensions are valid as indicators to measure the quality of customers' coffee shop experience. Further, by empirically testing the structural relationships among these quality assessment dimensions, satisfaction, self-efficacy and loyalty, this study provided theoretical foundations to explore the relationship between customer and the franchised stores in restaurant businesses. For the industry, the study findings showed that customers highly appreciated menu and economic quality of the service rather than the stores' interior. This indicate that the franchised coffee shops need to focus more on the basics of coffee such as taste and menu variety and economic value than the decoration of the store, which are often over-invested nowadays.
\end{abstract}

Keywords: Franchised Coffee Shop, Service Quality, Self-efficacy, Economic Quality, Satisfaction, Loyalty.

JEL Classification Code: M3, M21, M86.

\section{1. 서론}

국내 커피산업이 2018 년 매출액 기준으로 약 7 조 원에 달하며 세계적으로도 6 위의 커피 소비 국가로 자리매김 하였다(Park, 2019). 이와 같이 커피프랜차이즈 산업이 급속한 발전을 이루게 된 것은 국내 소비자들 사이에 원두 커피를 마시는 문화가 정착되었을 뿐 아니라 커피숍 등의 공간이 단순히 만남이나 음료를 마시는 장소만이 아닌 문화공간으로써 인식하게 되었고, 국내 외식브랜드에서 이러한

*Associate Professor, Yongin University, Department of Culture Tourism, South Korea, Email: soojin@yongin.ac.kr

๑ Copyright: Korean Distribution Science Association (KODISA)

This is an Open Access article distributed under the terms of the Creative Commons Attribution NonCommercial License (https://creativecommons.org/licenses/by-nc/4.0/) which permits unrestricted non-
소비자들의 요구를 만족시킬 서비스를 지속적으로 제공하였기 때문이다. 그러나 커피전문점의 수가 2016 년 기준으로 국내에 약 7 만개가 넘을 정도로 시장이 포화되고, 업체 간의 경쟁이 치열해 짐에 따라, 이러한 포화된 시장에서 생존하기 위해 차별화된 서비스 품질을 유지하여 경쟁력을 확보하고 고객만족과 충성도 있는 고객들을 유지하기 위한 전략 마련이 커피프랜차이즈 업계의 중요한 이슈로 등장하게 되었다(Lee, 2019; Susanty \& Kenny, 2015).

커피나 음료가 저관여 상품으로 여겨지지만, 커피 전문점의 서비스 품질은 단순한 커피의 맛이나 경제성으로만 평가되는 것이 아니라, 소비자들은 오히려 다양한 정보를 내재화하여 자신의 의사결정에 반영하는 것으로 밝혀졌다(Kelley, Hyde, \& Bruwer, 2015). 즉, 소비자들은 커피전문점의 서비스 품질을 평가할 때, 메뉴의 종류나 제공하는 
서비스 특성의 평가 시에는 내적인 암시(intinsic ue)를 물리적 환경과 경제성과 같은 상황적 요소들을 평가할 때는 외적인 암시(extrinsic cue)를 이용하여 서비스 품질을 평가하는 것으로 나타났다(Arboretti \& Bordignon, 2016. 그러나 커피전문점의 서비스에 대한 소비자들의 인식은 단순한 음료제공에서 머물지 않고 있으며 주변 환경이나 커피솝의 분위기 등의 무형적 서비스를 중요시하는 경향이 있다(Méndez, Oubiña, \& Rubio, 2011). 그러므로, 커피전문점과 같은 무형적 서비스에 대한 평가를 할 때는 소비자들은 내적 경로보다 외적 경로를 사용할 가능성이 높기 때문에, 고객의 서비스 품질을 설득하기 위해서는 외적인 암시를 활용한 소구전략이 효과적인 방법이 될 수 있을 것이다(Becker, 2000).

Heung and Gu(2012)는 외식업체의 서비스 품질 평가와 관련하여, 외적인 소비환경을 5 가지의 물리적 요소 - 시설의 심미성, 분위기, 공간 레이아웃, 종업원 요인 및 외부 경관 - 으로 구분하였는데 이러한 외적 환경이 서비스 품질 만족과 향후 재방문 의사에 긍정적인 영향을 미치는 것으로 나타났다. 또한, 최근의 연구에서는 서비스업체의 물리적 환경이 소비자의 브랜드에 대한 신뢰뿐 아니라 온라인에서 사회적 관계를 형성하려는 의도에도 영향을 주는 것으로 나타나 사회적인 영역까지 확대되고 있음을 알 수 있다(lang, Chang, \& Chen, 2015). 한편, 외식업체의 서비스 품질의 평가에는 이처럼 외부환경이나 물리적 측면뿐 아니라 메뉴나 서비스 전달 과정과 같은 내부 요소도 중요한 평가 요소로 인식되고 있다. Ryu, Lee, and Kim(2012)은 외식업체의 품질평가의 요소로 외부환경과, 음식의 질, 서비스로 구분하였는데, 외부환경 요인뿐 아니라 음식의 질과 서비스 품질이 모두 외식업체의 이미지와 서비스 가치에 긍정적인 영향을 미치는 것으로 나타났다. 이와 같이, 외식 프랜차이즈 매장 방문에 대한 소비자의 만족은 메뉴의 차원이나 물리적 환경 등의 개별적 요인에 의하여 결정되는 것이 아니라, 업체에 대한 다중적인 단서를 동시에 사용하여 서비스 품질에 대한 평가를 내린다Baker, Parasuraman, Grewal, and Voss, 2002).

무한경쟁 시장에서 살아남기 위해서 기업은 고객의 요구사항을 잘 파악하여 만족을 넘어 그들이 원하는 가치를 지속적으로 전달함으로써 충성도 있는 고객들을 유인하고, 이들과 상호 이익이 되는 관계를 유지해야 한다KKoter, Bowen, Makens \& Baloglu, 2017), 따라서 프랜차이즈 커피 업계에서도, 고객들의 요구사항을 잘 파악하여 그들과 지속적으로 소통하면서 어떤 부분에 만족하고 계속적으로 관계를 유지하고 싶어하는지에 대한 이해가 필요하다Mahon \& Cowan, 2004; Silayoi \& Speece, 2004). 그러나 커피프랜차이즈를 포함한 식음료 서비스 분야에서는 프랜차이즈 가맹본부와 프랜차이즈 가맹점 간의 충성도 구축 과정에 관한 연구는 활발하게 이루어져 있으나, 개별 고객들의 충성도를 구축하는 과정에 관한 연구는 아직 미비한 실정이다. 시장이 포화되어 치열한 경쟁을 겪고 있는 프랜차이즈 커피산업에서는 충성도 있는 고객을 유치하여 수익성 있는 관계를 맺는 것이 중요하고, 이를
위해서는 고객들이 프랜차이즈 커피전문점의 서비스 품질을 어떻게 평가하는 가를 파악하는 것이 중요한 이슈가 될 것이다.

따라서 본 연구는 프랜차이즈 커피전문점에 대한 고객의 서비스 품질 평가가 어떻게 만족과 충성도에 영향을 미치는 가의 영향 관계를 파악하려 하였다. 이를 위하여 프랜차이즈 커피전문점의 서비스 품질 평가요인을 메뉴, 환경, 서비스 및 경제적 요인의 4 가지로 구분하였으며, 품질평가 만족 및 충성도의 관계형성에 있어서 고객들의 자기 효능감이 어떠한 역할을 하는지도 파악하려 하였다. 본 연구 결과를 통해 프랜차이즈 커피업계에 서비스 품질 향상을 통해 충성 고객 유치하고 수익성 있는 관계를 유지하기 위한 전략적 제안을 제시할 수 있으리라 기대된다.

\section{2. 이론적 배경}

\section{1. 커피프랜차이즈의 서비스}

커피프랜차이즈와 같은 외식 산업에서 고객에게 평가되는 서비스 품질은 고객과 서비스 제공 업체 간의 관계를 기반으로 하기 때문에(Nikolich \& Sparks, 1995), 고객의 요구에 맞는 서비스를 설계할 필요가 있다. 커피프랜차이즈는 새로운 서비스 또는 개선된 서비스 시스템을 도입하기 전에 고객의 욕구를 파악해야 한다. 예를 들어 고객의 요구에 맞춰 메뉴의 가격, 인테리어, 그리고 시설과 같은 일반적인 매장의 환경을 경쟁사와 차별화하여 제공할 수 있다. 즉, 커피프랜차이즈는 고객에게 제공되는 메뉴와 서비스를 다양한 방법으로 설계할 수 있다.

소비자는 제품 또는 서비스를 선택하기 위해 정보를 검색하고 서비스에 대해 평가할 때, 추리하여 행동하는 경우가 많다(Bery, Wall, \& Carbone, 2006. 매장의 청결도를 통해 그 매장 메뉴의 위생을 추론하여 평가하는 경우가 많다. 믿을 수 있고 신속하고 정확한 무형의 서비스는 만족과 소비 후 행동에 영향을 미치는 단서로 제공될 수 있다Brady \& Robertson, 2001).

서비스 품질은 고객의 기대와 지각된 성과를 비교를 통해 형성된 고객의 주관적 평가이다Bolton \& Drew, 1991; Parasuraman, Zeithaml, \& Bemy, 1985). 고객의 반응에 가장 큰 영향을 미치는 요인 중 하나인 서비스 품질은 서비스마케팅 분야에서 광범위하게 연구되고 있다. 서비스 품질은 제공된 서비스에 대한 고객의 인지적 평가(Taylor \& Baker, 1994)와 서비스 속성의 평가에 의해 생성된 다차원 구조(Zeithaml, Beny, \& Parasuraman, 1988)의 두 가지 관점으로 연구되고 있다. 일반적으로 서비스 품질은 서비스에 대한 전반적인 우수성 또는 우위에 대한 고객의 판단으로 정의된다Zeithaml et al, 1988). 서비스와 관계된 
상황에서 SERVQUAL 은 서비스 품질을 측정하기 위해 이용되기도 한다(Canuana, Money, \& Berthon, 2000; Lee \& Lambert, 2000).

서비스 품질은 명확하게 정의하기 어려운 추상적인 개념으로 일부 문헌에서는 만족의 개념으로 사용되기도 한다(Lai \& Chen, 2011; Sumaedi, Mahatma \& Metasani, 2012). 많은 연구들이 서비스 품질 및 메뉴 품질이 고객 만족과 긍정적인 관계가 있다고 하였다(Canuana, Money, \& Berthon, 2000; Cronin, Brady, \& Hult, 2000; Namkung \& Jang, 2007). 그러나 서비스 품질과 만족은 다른 개념이다. Oliver(1997)에 의하면 만족은 정서적 판단에 의하여 결정되는 반면, 서비스 품질은 인지적 판단에 더 영향을 받는다고 하였다. 이러한 관점으로 보면, 서비스 품질은 외식 서비스를 설명하는 속성과 관계가 있다고 할 수 있다. 또한, 서비스 품질을 유일하게 평가할 수 있는 사람은 고객이다(Berry, Zeithaml, \& Parasuraman, 1990).

서비스 마케팅 분야에서 서비스 품질은 기능적 서비스 품질과 기술적 서비스 품질의 두 가지 차원으로 정의된다(Grönroos, 1984). 기능적 서비스 품질은 고객과 서비스 제공 업체 간의 상호작용과 관계가 있으며, 기술적 서비스 품질은 서비스 성과 품질을 나타낸다(Shama \& Patterson, 1999). 외식 산업에서 기능적 서비스 품질은 서비스 성과와 관계가 있는 반면, 기술적 서비스 품질은 메뉴 품질과 관계가 있다.

Rust and Oliver(1994)는 서비스 품질을 고객과 직원 간의 상호작용, 서비스 환경, 그리고 서비스 결과의 3 가지 요소가 포함된다고 하였다. Brady and Cronin(2001)도 서비스 품질을 서비스 제공 환경과 고객에게 제공되는 서비스에 대해 상호작용 품질, 물리적 환경 품질, 그리고 성과 품질의 3 가지 차원으로 제시하였다. 이러한 요인들은 경험적 서비스 품질을 긍정적으로 예측하는 요인으로 사용되고 있다(Brady \& Cronin, 2001). Brady and Cronin(2001)은 Rust and Olver(1994)의 연구를 기반으로 서비스 품질 개념을 상호작용 품질, 물리적 환경 품질, 그리고 결과 품질의 3 가지 차원으로 구분하였다. 상호작용 품질은 태도, 행동 및 전문 지식에 의해 측정되며, 물리적 환경 품질은 주변 조건, 디자인, 그리고 사회적 요인에 의해 측정된다. 또한 결과품질은 대기시간, 유형성에 의해 측정된다.

Ryu, Lee, and Kim(2012)는 서비스 품질을 구성하는 요인으로 메뉴 품질, 환경 품질, 그리고 상호작용 품질의 3 차원을 제시하였다. 본 연구에서는 Ryu et al.(2012)이 제시한 3 차원의 서비스 품질 요인에 경제적 품질을 추가하여 서비스 품질을 측정하였다. 서비스 품질 요인들과 관련하여 물리적 속성 등과 같은 인지적 요소 보다 정서적인 즐거움과 흥분 등의 감성적, 정서적 요소가 만족과 평가에 더 큰 영향을 미친다는 연구도 있기 때문에(Baloglu \& Brinberg, 1997), 경제적 품질과 환경 품질 이외에 상호작용 품질요인과 메뉴 품질 요인의 4 가지 구성 요인을 제시하였다 상호작용 품질은 경험 중에서 가장 중요한 요소 중 하나이기 때문에(Namkung \& Jang, 2007; Sulek \& Hensley, 2004) 상호작용 품질의 중요성은 다양하게 연구되어 왔다. Clark and Wood(1999)는 상호작용
품질이 매장 선택과 고객 충성도에 영향을 미치는 중요한 요인이라고 하였으며, Susskind and Chan(2000)는 고객 관점에서 상호작용 품질은 매장 방문의 핵심 결정 요인이라고 하였다. 또한, Mattia(2001)는 상호작용 품질을 고객 충성도 예측의 중요한 변수라고 하였으며, Sulek and Hensley(2004)는 환경 품질 및 서비스 품질과 같은 다른 요인과 비교할 때 상호작용 품질이 고객 만족의 가장 중요한 요인이라고 하였다.

고객의 서비스에 대한 평가와 행동은 서비스 제공 환경에 의해 결정된다(Kaplan, 1987). 물리적 환경은 고객이 일정 시간 동안 머물러야 하는 서비스와 관련하여 특히 중요하다(Wakefield \& Blodgett, 1996). 환경은 고객의 감정에 영향을 미치기 때문에 그 환경에 머무르거나 떠날 수 있다(Mehrabian \& Russell 1974). 물리적 환경은 고객이 경험하려고 하는 무형의 서비스를 평가하는데 있어서 고객이 이용할 수 있는 중요한 유형의 자원이다(Edvardsson, Enquist, \& Johnston, 2010). Edvardsson et al.(2010)은 고객은 사용 전 물리적 환경 품질(예: 조명, 장식 및 레이아웃)을 통해 예상되는 서비스 경험을 유추 할 수 있다고 하였다.

Namkung and Jang(2007)은 메뉴 품질이 고객 만족과 행동의도에 미치는 영향을 조사하여 메뉴 품질과 만족 및 행동의도 간에 긍정적인 영향 관계가 있다고 하였다. 메뉴 품질은 다양한 속성을 이용하여 측정되고 있다. Kivela, Inbakaran, and Reece(2000)는 메뉴 품질을 음식의 맛 메뉴의 다양성, 그리고 영양에 대한 몇 가지 특수성을 고려하여 메뉴가 고객 만족과 재구매에 미치는 영향을 연구하였으며, Raajpoot(2002)는 메뉴 서비스, 제품 크기, 메뉴 디자인 및 메뉴 품질을 측정하기 위해 다양한 음식을 사용했다. Sulek and Hensley(2004)도 메뉴 품질은 안전성, 매력, 그리고 식이 수용성의 세 가지 일반적 특성이라고 하였으며, Namkung and Jang(2007)은 메뉴 품질을 평가하기 위해 디자인, 메뉴의 다양성, 건강, 맛, 신선도 및 메뉴의 온도로 측정하였다.

경제적 품질은 구매 전 고객의 품질 평가에 영향을 미칠 뿐만 아니라 구매 후 평가에도 영향을 미친다. 경제적 품질은 지각된 혜택과 비용의 차이다. 고객은 제품 또는 서비스 구매 가격에 따라 품질을 인식하는 경향이 있다(Korda \& Snoj, 2007). 커피프랜차이즈와 같은 서비스 산업에서도 가격이 고객의 구매에 영향을 중요한 요인이다(Lu \& Feng, 2009).

\section{2. 만족}

서비스 품질과 만족은 다른 요소로 고객이 고품질의 서비스를 인식하면 만족할 수 있다(Hurley \& Estelami, 1998). 고객 만족은 특히 서비스 기업의 성과에 중요한 영향을 미치는 요인이기 때문에 기업의 목표 중 하나이다(Jones \& Sasser, 1995). 
만족은 고객의 제품 또는 서비스에 대한 기대보다 성과를 높게 인식하여 긍정적인 감정이 형성된 정도로 정의된다(Oliver, 1981). 또한, 만족은 고객이 제공받는 서비스가 긍정적인 반응을 불러오는 정도로 정의된다Zhong, Busser, \& Baloglu, 2017). 만족과는 반대로 불만족은 구매 전 기대와 구매 후 혜택의 불일치를 의미한다-Hussain, Mkpojiogu, \& Yusof, 2016. 커피프랜차이즈에 대한 만족은 매장 방문 전 기대와 매장 방문 후 성과에 대한 차이로 평가된다. 고객은 기대에 비해 성과가 크면 만족한다. 그러나 기대에 대한 성과가 낮으면 고객은 불만족할 수 있다(Moon, Costello, \& Koo, 2017).

\section{3. 자기 효능감}

자기 효능감은 과업을 수행하는 능력에 대한 자신의 신념으로 역할 수행의 핵심 과제이다Gist, 1987). 그러나 고객의 환경에 대한 자기 효능감은 정해진 행동이 아니며, 단순히 무엇을 해야 하는지를 아는 문제가 아니다(Bandura, 1982). 즉, 지식과 자기 효능감은 명확하게 구분된다(Ozer \& Bandura, 1990). 사람들이 필요한 기술을 보유하고 무엇을 해야 하는지 알고 있더라도 최적의 성과를 달성하지 못하는 경우가 많다.

사업 환경에서 자기 효능감은 목표 설정이 포함된 고객의 태도와 행동을 설명하는데 이용된다(Brown, Cron, \& Slocum 1998). 이러한 자기 효능감은 행동 의도의 매개 역할을 한다(Bandura, 1982). 고객은 행동하는데 필요한 지식과 기술을 가지고 있으면 편하게 행동할 수 있다. 즉, 고객은 행동하기 전에 자신이 커피프랜차이즈를 이용하고자 하는 신념이라고 할 수 있다. 신념은 긍정적인 행동을 수행할 수 있도록 동기를 부여한다(Strieter, Celuch, \& Kasouf 1999).

\section{4. 충성도}

과거에는 충성도가 제품 또는 서비스의 구매 행동, 추천 및 반복 구매 빈도를 측정하는 행동 개념으로 인식되었다(Hallowell, 1996). 그러나 Bemé, Múgica, and Yagüe(2001)는 충성도가 행동 충성도만 존재하지 않고 태도 충성도도 존재한다고 하였다. 태도 충성도는 고객이 제품 또는 서비스에 대한 긍정적인 태도 또는 평가를 하는 심리적인 상태이다Rai \& Sivivastava, 2012). 커피 프랜차이즈에서 고객 충성도는 음료에 대한 품질뿐만 아니라 고객의 심리 상태가 포함된 직원과의 상호작용에 의해서도 충성도가 형성되기 때문이다Shin, Hwang, Lee, \& Cho, 2015).

\section{1. 커피프랜차이즈의 서비스 품질과 만족간의} 관계

서비스 산업에서 고객 만족은 서비스 품질에 중점을 두고 있다(Parasuraman et al, 1988). 서비스 마케팅에서 서비스 품질과 만족은 기업의 성과를 예측하는 주요 요인이다(Cronin et al, 2000). 서비스 품질은 만족과 행동의도에 영향을 미치는 중요한 요인 중 하나이다Chen, 2008; Chen \& Tsai, 2007). 또한, 서비스 품질은 만족에 영향을 미치고, 만족은 충성도에 영향을 미친다(Bigne, Sanchez, \& Sanchez, 2001; Chen \& Tsai, 2007; Petrick \& Badkman, 2002).

이와 같은 선행연구를 바탕으로 외식프랜차이즈의 서비스 품질과 만족 간의 가설을 다음과 같이 설정하였다.

H1: 외식프랜차이즈의 서비스 품질은 만족에 정(+)의 영향을 미칠 것이다.

H1-1: 메뉴 품질은 만족에 정(+)의 영향을 미칠 것이다.

H1-2: 환경 품질은 만족에 정(+)의 영향을 미칠 것이다.

H1-3: 상호작용 품질은 만족에 정(+)의 영향을 미칠 것이다.

H1-4: 경제적 품질은 만족에 정(+)의 영향을 미칠 것이다.

\section{2. 서비스 품질과 자기 효능감 간의 관계}

자기 효능감은 고객이 서비스에 관여할 때 발생할 수 있다Ford \& Dickson, 2012). 즉, 서비스의 비분리성으로 인해 고객은 서비스에 관여하고 자기 효능감이 발생할 수 있다. 고객이 커피프랜차이즈를 지속적으로 이용하려면, 고품질의 서비스를 제공받을 수 있는 자신감이 필요하다(Limayem, Hirt, \& Cheung, 2007).

이와 같은 선행연구를 바탕으로 외식프랜차이즈의 서비스 품질과 자기 효능감 간의 가설을 다음과 같이 설정하였다.

H2: 외식프랜차이즈의 품질은 자기 효능감에 정(+)의 영향을 미칠 것이다.

H2-1: 메뉴 품질은 자기 효능감에 정(+)의 영향을 미칠 것이다.

H2-2: 환경 품질은 자기 효능감에 정( $(+)$ 의 영향을 미칠 것이다.

H2-3: 상호작용 품질은 자기 효능감에 정( + )의 영향을 미칠 것이다.

H2-4: 경제적 품질은 자기 효능감에 정( $(+)$ 의 영향을 미칠 것이다.

\section{3. 만족 및 자기 효능감과 충성도 간의 관계}

McKee, Simmers, and Licata(2006)는 자기 효능감이 고객의 행동 의도와 관계가 있다고 하였다. 자기 효능감은 고객의 기본적인 능력을 통한 
행동 의도를 예측하는데 널리 사용하며 자기 효능감 이론은 목표 설정 등 다양한 비즈니스와 관계된 태도와 행동을 설명하는 데 사용되었다(Brown, Cron, \& Slocum, 1998). 더 불만스러운 고객은 대상에 대한 부정적인 의견을 표명하고 시장 평판을 손상시킬 수 있다(Reisinger \& Tumer, 2003). 또한, 만족은 행동 의도에 직접적으로 영향을 미치는 중요한 요인이다(Petrick \& Backman, 2002).

이와 같은 선행연구를 바탕으로 만족 및 지기효능감과 충성도 간의 가설을 다음과 같이 설정하였다.

$\mathrm{H3}$ : 만족은 자기 효능감에 정(+)의 영향을 미칠 것이다.

$\mathrm{H} 4$ : 만족은 충성도에 정(+)의 영향을 미칠 것이다.

$\mathrm{H} 5$ : 자기 효능감은 충성도에 정(+)의 영향을 미칠 것이다.

\section{4. 연구 방법}

\section{1. 표본의 설계}

본 연구의 연구에 필요한 설문은 온라인 설문조사 전문기관을 통해 조사되었다. 설문조사는 최근 1 개월 이내에 커피전문점을 방문 경험이 있는 온라인 설문조사 전문기관의 패널을 대상으로 2019 년 2 월 11 일부터 2 월 14 일까지 총 5 일 간 실시되었으며, 총 332 부의 설문 중 불성실한 설문 4 부를 제외한 318 부가 분석에 이용되었다.

설문은 SPSS 21.0 과 AMOS 21.0 프로그램을 이용하여 분석되었다. 표본의 일반적 특성은 빈도분석이 이용되었으며, 각 연구 단위에 대한 단일 차원성 검증은 확인적 요인분석이 이용되었다. 또한, 연구 단위들 간의 상관관계가 분석되었으며, 연구가설 검증을 위해 구조방정식 모형을 사용하였다.

\section{2. 변수의 조작적 정의 및 측정}

가설 검증을 위한 모든 측정 항목은 "1 점=전혀 그렇지 않다"에서 "7 점=매우 그렇다"의 7 점 척도로 측정되었다. 본 연구에 이용된 메뉴 품질, 환경 품질, 그리고 서비스 품질은 Ryu et al(2012)의 이용하여 각각 4 개 항목으로 측정되었다. 메뉴 품질은 커피프랜차이즈 메뉴가 훌륭한 정도로 정의되었으며, 환경 품질은 커피프랜차이즈 인테리어(interior)와 익스테리어(extenior) 품질로 정의되었다. 또한, 상호작용 품질은 커피프랜차이즈 서비스의 정확하고 신속한 정도로 정의되었다.

경제적 품질은 5 개 항목으로 측정되었다. 경제적 품질은 커피프랜차이즈 서비스 비용에 대한 혜택으로 정의되었다. 환경 품질과 서비스 품질은 Ryu, et al(2012)의 연구를 이용하여 각각 4 개 항목으로 측정되었다.
만족은 Lee, Lee, and Yoo(2000)의 연구를 이용하여 5 개 항목으로 측정되었으며, 고객의 기대에 대한 성과로 정의되었다. 자기 효능감은 Hildebrand and Betts(2009)의 연구를 이용하여 5 개 항목으로 측정되었으며, 커피프랜차이즈 서비스를 편하고 자유롭게 이용하는 정도로 정의되었다. 또한, 충성도는 Zeithaml et al(1996)의 연구를 이용하여 4 개 항목으로 측정되었으며, 고객이 커피프랜차이즈에 대해 구전 의도와 재방문 의도로 정의되었다.

\section{5. 실증분석}

\section{1. 표본의 일반적 특성}

본 연구에 이용된 표본( $\mathrm{n}=318)$ 의 일반적 특성은 Table: 1 과 같다. 먼저, 성별은 여자가 40.3\%(128 명), 남자가 59.7\%(190 명)로 나타났으며, 결혼 유무는 미혼이 56.6\%(180 명), 기혼이 43.4\%(138 명)로 나타났다.

Table 1: Demographic Profile of the Respondents ( $n=318)$

\begin{tabular}{|c|c|c|c|}
\hline & & $\mathbf{n}$ & $\%$ \\
\hline \multirow{2}{*}{ Gender } & Male & 128 & 40.3 \\
\hline & Female & 190 & 59.7 \\
\hline \multirow{2}{*}{ Marital status } & Single & 180 & 56.6 \\
\hline & Married & 138 & 43.4 \\
\hline \multirow{5}{*}{ Age } & Below 19 & 1 & 0.3 \\
\hline & $20-29$ & 58 & 18.2 \\
\hline & $30-39$ & 174 & 54.7 \\
\hline & $40-49$ & 84 & 26.4 \\
\hline & $50-59$ & 1 & 0.3 \\
\hline \multirow{4}{*}{$\begin{array}{l}\text { Educational } \\
\text { level }\end{array}$} & Below high school & 27 & 8.5 \\
\hline & Undergraduate & 34 & 10.7 \\
\hline & 4 year university & 228 & 71.7 \\
\hline & Graduate school & 29 & 9.1 \\
\hline \multirow{7}{*}{ Job } & Student & 18 & 5.7 \\
\hline & Officer & 174 & 54.7 \\
\hline & Professional & 39 & 12.3 \\
\hline & Sales & 19 & 6 \\
\hline & Technical & 11 & 3.5 \\
\hline & Housewife & 45 & 14.2 \\
\hline & Others & 12 & 3.8 \\
\hline \multirow{5}{*}{$\begin{array}{l}\text { Monthly visit } \\
\text { frequency }\end{array}$} & Below 5 & 25 & 7.9 \\
\hline & $6 \sim 10$ & 185 & 58.2 \\
\hline & $11 \sim 15$ & 84 & 26.4 \\
\hline & $16 \sim 20$ & 17 & 5.3 \\
\hline & Over 21 & 7 & 2.2 \\
\hline
\end{tabular}


연령대는 30 대가 54.7\%(174 명)로 가장 많고, 다음으로 40 대 26.4\% (84 명), 20 대 18.2\%(58 명), 그리고 19 세 이하와 50 대가 각각 $0.3 \%(1$ 명)의 순으로 나타났다. 최종 학력은 대학교(재학) 졸업이 $717 \%(228$ 명)로 가장 많았고, 다음으로 전문대(재학)졸업이 $10.7 \%(34$ 명), 대학원이상이 91\%(29 명), 그리고 고졸(이하)이 8.5\%(27 명)의 순으로 나타났다. 직업은 사무직이 54.7\%(174 명)로 가장 많이 나타났으며, 다음으로 가정주부가 $142 \%(45$ 명), 전문직이 12.3\%(39 명), 서비스직이 6.0\%(19 명), 학생이 $5.7 \%$ (18 명), 기타/무직이 $3.8 \%(12$ 명), 그리고 기술/생산직이 $3.5 \%(11$ 명)의 순으로 나타났다.

월 평균 커피프랜차이즈 방문 횟수는 6 회 10 회가 58.2\%(185 명)로 가장 많이 나타났으며, 다음으로 11 회 15 회가 26.4\%(84 명), 5 회 이하가 79\%(25 명), 16 회 20 회가 53\%(17 명), 그리고 21 회 이상이 22\%(7 명)의 순으로 나타났다.

\section{2. 측정모형 분석}

척도들의 집중타당성(convergent validity)과 판별타당성(discriminant validity)을 검증하기 위하여 본 연구모형에 포함된 모든 연구 단위들에 대한 측정모형분석(measurement model analysis)이 실시되었다.

분석 결과, Table: 2 에서와 같이, 적합도 지수는 $\chi^{2}=588.087(\mathrm{df}=320$, $\chi^{2} / \mathrm{df}=1838, p$-value $\left.=0.000\right), \mathrm{CH}=0.962, \mathrm{NH}=0.921, \mathrm{GH}=0.883, \mathrm{AGH}=0.852$, $\mathrm{RMR}=0.064, \mathrm{RMSEA}=0.051$ 로 나타나 구조모형 분석 이용에 적합한 것으로 나타났다.

Table 2: Measurement Model Resulting from Confirmatory Factor Analysis

\begin{tabular}{|c|c|c|c|}
\hline Items & $\begin{array}{l}\text { Standardized } \\
\text { Factor Loading }\end{array}$ & CCR & AVE \\
\hline \multicolumn{2}{|l|}{ Menu Quality } & \multirow{5}{*}{0.859} & \multirow{5}{*}{0.648} \\
\hline Delicious food/drinks & 0.855 & & \\
\hline Nutritious food/drinks & 0.815 & & \\
\hline Extensive menu & 0.754 & & \\
\hline Good-looking food & 0.792 & & \\
\hline \multicolumn{2}{|l|}{ Environmental Quality } & \multirow{5}{*}{0.777} & \multirow{5}{*}{0.613} \\
\hline Attractive in-store layout & 0.733 & & \\
\hline Pleasant in-store sound & 0.812 & & \\
\hline Cleanliness of the store & 0.802 & & \\
\hline Tidiness of employees & - & & \\
\hline \multicolumn{2}{|l|}{ Interaction Quality } & \multirow{4}{*}{0.788} & \multirow{4}{*}{0.542} \\
\hline Accuracy of service delivery & 0.686 & & \\
\hline $\begin{array}{l}\text { Promptness of service } \\
\text { delivery }\end{array}$ & 0.759 & & \\
\hline Helpfulness of employees & 0.753 & & \\
\hline
\end{tabular}

\begin{tabular}{|c|c|c|c|}
\hline Kindliness of employees & 0.745 & & \\
\hline \multicolumn{2}{|l|}{ Economic Quality } & \multirow{6}{*}{0.882} & \multirow{6}{*}{0.764} \\
\hline Good price & 0.837 & & \\
\hline Good value for the food & - & & \\
\hline Fair price & 0.876 & & \\
\hline Reasonable price & 0.906 & & \\
\hline Economic price & 0.876 & & \\
\hline \multicolumn{2}{|l|}{ Satisfaction } & \multirow{6}{*}{0.84} & \multirow{6}{*}{0.626} \\
\hline $\begin{array}{l}\text { Satisfied with visiting the } \\
\text { store }\end{array}$ & 0.88 & & \\
\hline $\begin{array}{l}\text { Appreciate highly with the } \\
\text { store }\end{array}$ & 0.811 & & \\
\hline $\begin{array}{l}\text { Emotionally satisfied with } \\
\text { the overall experience with } \\
\text { the store }\end{array}$ & - & & \\
\hline $\begin{array}{l}\text { In general, I am satisfied with } \\
\text { the store }\end{array}$ & 0.724 & & \\
\hline $\begin{array}{l}\text { Satisfied with the service } \\
\text { quality of the store }\end{array}$ & 0.739 & & \\
\hline \multicolumn{2}{|l|}{ Self-efficacy } & \multirow{6}{*}{0.864} & \multirow{6}{*}{0.62} \\
\hline $\begin{array}{l}\text { Competent to evaluate the } \\
\text { store }\end{array}$ & 0.687 & & \\
\hline $\begin{array}{l}\text { Confident to talk about the } \\
\text { store }\end{array}$ & 0.791 & & \\
\hline $\begin{array}{l}\text { Easily use the services of the } \\
\text { store }\end{array}$ & 0.849 & & \\
\hline $\begin{array}{l}\text { Know well how to use the } \\
\text { services of the store }\end{array}$ & 0.805 & & \\
\hline $\begin{array}{l}\text { The store matches well with } \\
\text { my image }\end{array}$ & 0.797 & & \\
\hline \multicolumn{2}{|l|}{ Loyalty } & \multirow{5}{*}{0.862} & \multirow{5}{*}{0.706} \\
\hline $\begin{array}{l}\text { Intend to visit the store in the } \\
\text { future }\end{array}$ & 0.82 & & \\
\hline $\begin{array}{l}\text { Likely to visit the store in the } \\
\text { future }\end{array}$ & 0.843 & & \\
\hline $\begin{array}{l}\text { Plan to visit the store more } \\
\text { actively }\end{array}$ & 0.852 & & \\
\hline $\begin{array}{l}\text { Recommend others to visit } \\
\text { the store }\end{array}$ & 0.845 & & \\
\hline
\end{tabular}

a $\chi^{2}=337.323(\mathrm{df}=173, \chi 2 / \mathrm{df}=1.950, \quad \mathrm{p}$-value $=0.000), \quad \mathrm{CFI}=0.962$, $\mathrm{NFI}=0.925, \mathrm{GFI}=0.901, \mathrm{RMR}=0.075, \mathrm{RMSEA}=0.056$

${ }^{\mathrm{b}} \mathrm{CCR}$ (Composite construct reliability)

${ }^{c}$ AVE(Average variance extracted)

* Items were deleted during confirmatory factor analysis.

\section{3. 상관관계 분석}

타당성과 신뢰도 분석 결과, 단일차원성이 입증된 각 연구 단위 별 척도들에 대하여 서로의 관계가 어떤 방향이며, 어느 정도의 
상관관계를 갖는지 알아보기 위하여 상관관계 분석을 실시한 결과, Table: 3 에서와 같이, 연구모형과 연구가설에서 제시한 연구 단위들 간의 관계 방향은 일치하는 것으로 나타났다.

\section{4. 연구가설의 검증}

본 연구에 이용된 외식프랜차이즈의 서비스 품질, 만족, 자기 효능감 그리고 충성도와 같은 연구 단위들 간의 전체적 모형을 구조방정식 모형(SEM)으로 검증한 결과, 적합도는 $\chi 2=614.474(\mathrm{df}=324, \chi 2 / \mathrm{df}=1.897, \mathrm{p}-$ value=0.000), GH=0.877, AGH=0.846, NH=0.917, CH=0.959, RMR=0.071, RMSEA $=0.053$ 으로 나타났다. 또한, 내생변수가 외생변수에 의해서 설명되는 설명력 $\left(R^{2}\right)$ 를 분석한 결과, 만족은 $0.910(90.1 \%)$, 자기 효능감은 $0.811(81.1 \%)$, 충성도는 $0.784(78.4 \%)$ 로 나타났다.

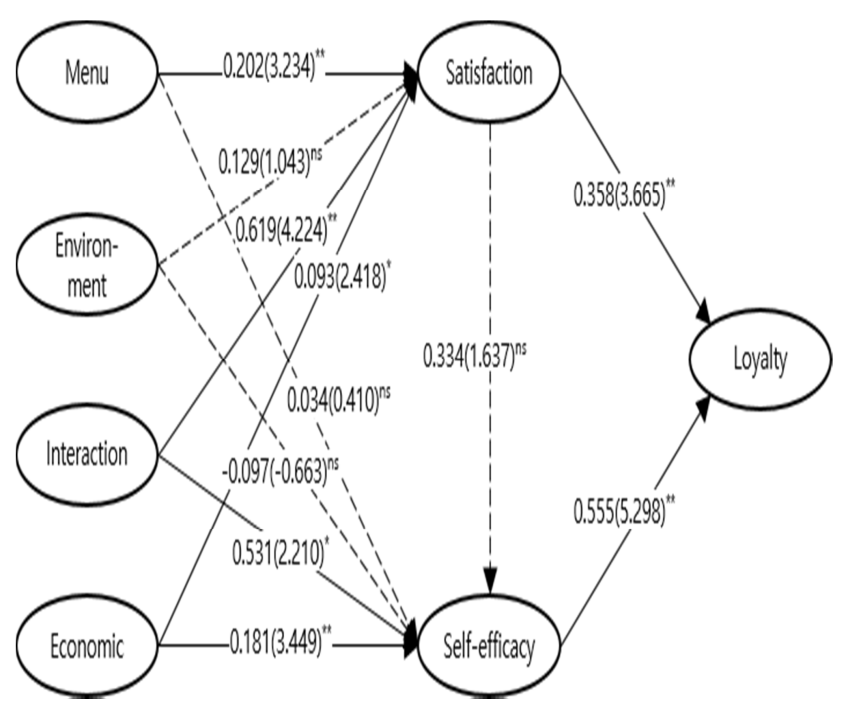

$* * \mathrm{p}<0.01, * \mathrm{p}<0.05$

$\chi^{2}=614.474\left(\mathrm{df}=324, \quad \chi^{2} / \mathrm{df}=1.897, \quad \mathrm{p}\right.$-value $\left.=0.000\right), \quad$ GFI=0.877, $\mathrm{AGFI}=0.846, \mathrm{NFI}=0.917, \mathrm{CFI}=0.959, \mathrm{RMR}=0.071, \mathrm{RMSEA}=0.053$

Figure 1: Estimates of the Structural Model

본 연구에 이용된 외식프랜차이즈의 서비스 품질, 만족, 자기 효능감, 그리고 충성도와 같은 연구 단위들간의 관계에 대한 가설을 검증하기 위하여 구조모형을 분석한 결과는 Table: 4 와 같다. 상관관계 분석 결과 상호작용 품질과 만족 간의 상관관계의 제곱 값이 AVE 보다 높게 나타났으나, 본 연구에서는 서비스 품질이 만족에 미치는 영향관계를 검증하기 위한 것으로 추후 분석에 이용되었다.

메뉴 품질이 만족에 긍정적(+) 영향을 미칠 것이라는 $\mathrm{H} 1-1$ 을 검증한 결과, 경로계수 값은 0202 , t 값은 3.234 로 메뉴 품질은 만족에
통계적으로 유의한 정(+)의 영향을 미치는 것으로 나타났다(p<0.05). 따라서 $\mathrm{H1}-1$ 은 채택되었다.

환경 품질이 만족에 긍정적(+) 영향을 미칠 것이라는 $\mathrm{H1}-2$ 를 검증한 결과, 경로계수 값은 $0.129, \mathrm{t}$ 값은 1.043 으로 환경 품질은 만족에 통계적으로 유의한 정(+)의 영향을 미치지 않는 것으로 나타났다(p>0.05). 따라서 H1-2 는 기각되었다. 상호작용 품질이 만족에 긍정적(+) 영향을 미칠 것이라는 H1-3을 검증한 결과, 경로계수 값은 0.619 , t값은 4.224로 상호작용 품질은 만족에 통계적으로 유의한 정(+)의 영향을 미치는 것으로 나타났다(p<0.05). 따라서 H1-3 은 채택되었다. 경제적 품질이 만족에 긍정적(+) 영향을 미칠 것이라는 $\mathrm{H} 1-4$ 를 검증한 결과, 경로계수 값은 $0.093, \mathrm{t}$ 값은 2.418 로 경제적 품질은 만족에 통계적으로 유의한 정(+)의 영향을 미치는 것으로 나타났다 $(\mathrm{p}<0.05)$. 따라서 $\mathrm{H1}-4$ 는 채택되었다.

메뉴 품질이 자기 효능감에 긍정적(+) 영향을 미칠 것이라는 H2-1을 검증한 결과, 경로계수 값은 $0.034, \mathrm{t}$ 값은 0.410 으로 메뉴 품질은 자기 효능감에 통계적으로 유의한 정(+)의 영향을 미치지 않는 것으로 나타났다( $p>0.05)$. 따라서 $\mathrm{H} 2-1$ 은 기각되었다. 환경 품질이 자기 효능감에 긍정적(+) 영향을 미칠 것이라는 $\mathrm{H} 2-2$ 를 검증한 결과, 경로계수 값은 $-0.097, \mathrm{t}$ 값은 -0.663 으로 환경 품질은 자기 효능감에 통계적으로 유의한 정(+)의 영향을 미치지 않는 것으로 나타났다( $p>0.05)$ 따라서 H2-2 는 기각되었다. 상호작용 품질이 자기 효능감에 긍정적(+) 영향을 미칠 것이라는 H2-3을 검증한 결과, 경로계수 값은 0.531, t값은 2210 으로 상호작용 품질은 자기 효능감에 통계적으로 유의한 정(+)의 영향을 미치는 것으로 나타났다(p<0.05). 따라서 H2-3 은 채택되었다. 경제적 품질이 자기 효능감에 긍정적(+) 영향을 미칠 것이라는 $\mathrm{H} 2-4$ 를 검증한 결과, 경로계수 값은 $0.181, \mathrm{t}$ 값은 3.449 로 경제적 품질은 자기 효능감에 통계적으로 유의한 정(+)의 영향을 미치는 것으로 나타났다 $(\mathrm{p}<0.05)$. 따라서 $\mathrm{H} 2-4$ 는 채택되었다.

만족이 자기 효능감에 긍정적(+) 영향을 미칠 것이라는 $\mathrm{H3}$ 을 검증한 결과, 경로계수 값은 $0.334, \mathrm{t}$ 값은 1.637 로 만족은 자기 효능감에 통계적으로 유의한 정(+)의 영향을 미치지 않는 것으로 나타났다(p>0.05). 따라서 $\mathrm{H} 3$ 은 기각되었다. 만족이 충성도에 긍정적(+) 영향을 미칠 것이라는 $\mathrm{H} 4$ 를 검증한 결과, 경로계수 값은 $0358, \mathrm{t}$ 값은 3.665 로 만족은 충성도에 통계적으로 유의한 정(+)의 영향을 미치는 것으로 나타났다(p<0.05). 따라서 $\mathrm{H} 4$ 는 채택되었다.

자기 효능감이 충성도에 긍정적(+) 영향을 미칠 것이라는 $\mathrm{H} 5$ 를 검증한 결과, 경로계수 값은 $0.555, \mathrm{t}$ 값은 5298 로 자기 효능감은 충성도에 통계적으로 유의한 정(+)의 영향을 미치는 것으로 나타났다(p<0.05). 따라서 H5는 채택되었다. 
Table 3: Construct Inter correlations, Mean and Standard Deviation

\begin{tabular}{|c|c|c|c|c|c|c|c|}
\hline & Menu Quality & $\begin{array}{c}\text { Environmental } \\
\text { Quality }\end{array}$ & $\begin{array}{c}\text { Interaction } \\
\text { Quality }\end{array}$ & $\begin{array}{c}\text { Economic } \\
\text { Quality }\end{array}$ & Satisfaction & Self-Efficacy & Loyalty \\
\hline Menu Quality & 1 & & & & & & \\
\hline Environmental quality & $0.600^{* *}$ & 1 & & & & & \\
\hline Interaction Quality & $0.635^{* *}$ & $0.730^{* *}$ & 1 & & & & \\
\hline Economic Quality & $0.556^{* *}$ & $0.391^{* *}$ & $0.380^{* *}$ & 1 & & & \\
\hline Satisfaction & $0.715^{* *}$ & $0.745^{* *}$ & $0.830^{* *}$ & $0.507^{* *}$ & 1 & & \\
\hline Self-Efficacy & $0.667^{* *}$ & $0.679^{* *}$ & $0.743^{* *}$ & $0.524^{* *}$ & $0.783^{* *}$ & 1 & \\
\hline Loyalty & $0.663^{* *}$ & $0.639^{* *}$ & $0.651^{* *}$ & $0.597^{* *}$ & $0.747^{* *}$ & $0.768^{* *}$ & 1 \\
\hline Mean & 4.803 & 5.024 & 5.046 & 4.119 & 4.97 & 4.884 & 4.856 \\
\hline S.D. & 0.945 & 0.999 & 0.946 & 1.205 & 0.946 & 0.943 & 1.108 \\
\hline
\end{tabular}

Table 4: Standardized Parameter Estimates

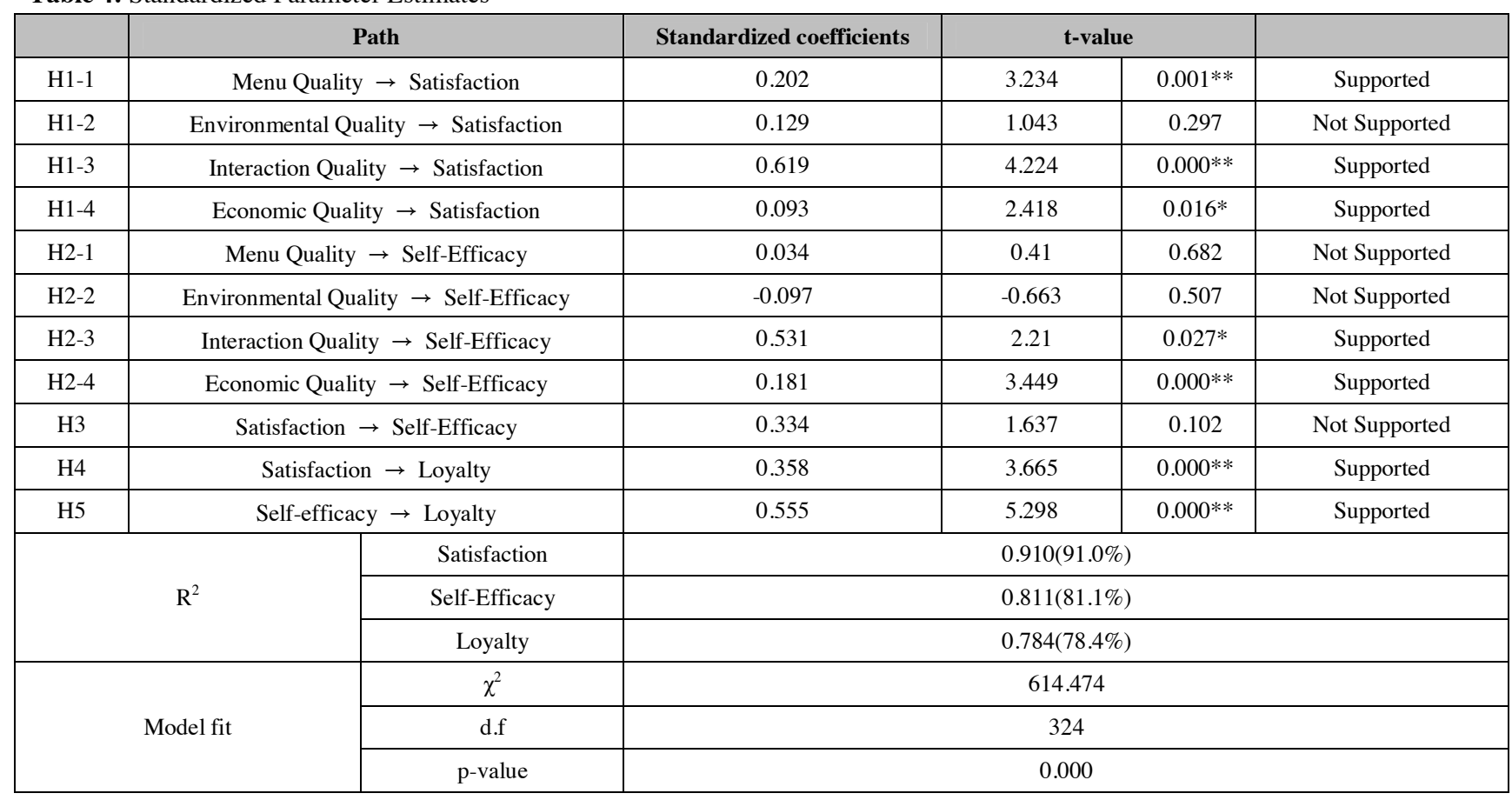

$* \mathrm{p}<0.01, * * \mathrm{p}<0.001$, n.s.: not significant

$\chi^{2}=614.474\left(\mathrm{df}=324, \chi^{2} / \mathrm{df}=1.897, \mathrm{p}-\mathrm{value}=0.000\right), \mathrm{GFI}=0.877, \mathrm{AGFI}=0.846, \mathrm{NFI}=0.917, \mathrm{CFI}=0.959, \mathrm{RMR}=0.071, \mathrm{RMSEA}=0.053$

\section{5. 결론}

본 연구는 커피프랜차이즈를 대상으로 프랜차이즈 매장의 서비스 품질에 대한 고객 만족, 자기 효능감, 그리고 충성도가 어떠한 영향을 할 것이라는 가정으로 이들 요인 간의 구조 관계를 설정하여 분석한 결과 다음과 같은 학술적 의의가 있다.

첫째, 선행 연구에서는 주로 서비스 품질을 메뉴 품질, 환경 품질, 그리고 상호작용 품질로 구분하였으나(Ryu et al., 2012), 본 연구에서는
커피프랜차이즈의 서비스 품질평가 요인에 경제적 품질 요인을 추가하였다. 또한, 연구 결과 이 경제적 품질 요인이 고객충성도에 영향을 미치는 것으로 나타나, 커피프랜차이즈의 음료 가격이 지속적으로 높아지는 상황에서 고객의 서비스 평가 요인으로 경제적 품질이 중요하다는 발견하여 앞으로 커피 및 음료 프랜차이즈 관련 연구자들에게 학술적 의의가 있다.

둘째, 본 연구는 커피프랜차이즈의 서비스 품질이 고객 충성도에 미치는 영향을 B2C 관점에서 실증 분석함으로써, 고객을 직접 응대하지 
않고 가맹점을 통해 응대하는 가맹본부의 서비스품질에 대한 이론적 기틀을 마련하였다. 이러한 연구는 비슷한 관계에 있는 제조업체대리점-소비자 및 제조업체-판매점-소비자에도 확대 연구할 수 있는 기초를 제공하였다는 점에서 의의가 있다.

셋째, 본 연구에서 환경 품질은 만족과 자기 효능감에 유의한 영향을 미치지 않는 것으로 나타났다. 이러한 연구는 물리적 환경이 만족에 영향을 미치는 것으로 연구한 Ryu et al.(2012)의 연구와 다르게 나타났다. 이러한 연구 결과는 대부분의 커피프랜차이즈 매장들의 물리적 환경이 고객의 기대 이상으로 설계되었기 때문일 수 있다. 커피프랜차이즈 매장은 외식프랜차이즈 매장보다 인테리어에 더 많은 비용을 들이고 자주 바꾸기 때문일 것이다.

넷째, 소비자의 충성도 형성에 대해 서비스 품질 이론을 커피프랜차이즈 분야에 맞게 재해석하였다. 특히, 커피프랜차이즈 매장이 급격히 증가하고 있는 상황에서 충성도에 대한 이론적 접근은 향후 가맹본부가 소비자에게 제공할 수 있는 서비스 품질 개념으로 정립되어야 한다.

본 연구의 실무적 시사점은 다음과 같다.

첫째, 커피프랜차이즈는 소비자가 선호하는 고품질의 메뉴를 제공해야 한다. 고객이 커피프랜차이즈 매장을 방문하는 이유 중 가장 큰 이유는 음료를 즐기기 위해서 일 것이다. 즉, 커피프랜차이즈 기업은 지속적인 메뉴 개발 및 개선을 통해 고객의 요구에 부응해야 한다. 예를 들어, 고객은 매장 환경을 보고 음료에 대한 기대가 형성된다. 매장 환경이 고급스러우면 메뉴 품질도 좋아야 하지만, 그렇지 않으면 고객은 실망하여 다시 찾지 않을 것이다.

둘째, 커피프랜차이즈는 장기적인 충성 고객으로 유지하기 위해서는 소비자에게 많은 관심을 가져야 한다. 소비자가 인지하고 있는 서비스 품질을 개선하려는 노력을 통해 소비자의 만족을 얻는다면 고객 충성도가 강화될 것이다. 예를 들어, 서비스 제공자가 고객의 음료 취향을 기억하여 제공하면, 고객은 그 프랜차이즈에 대해 긍정적으로 평가하여 충성도를 가질 것이다.

셋째, 커피프랜차이즈는 지속적인 서비스 교육을 통해 서비스 품질을 개선해야 한다. 고객은 직원의 서비스가 좋지 않으면, 기분이 나쁠 수 있다. 고객의 서비스 평가는 감정적 평가도 포함되어 있기 때문이다. 많은 커피프랜차이즈가 가맹점의 서비스 교육을 개점 초기에만 지원하고 지속적으로 지원하지 않는 경우가 많다. 또한, 가맹점도 지속적으로 서비스 교육을 받게 되면 비용이 지불되기 때문에 싫어하는 경우가 많다. 이러한 악순환은 결과적으로 서비스 품질에 영향을 미칠 수밖에 없다.

넷째, 커피프랜차이즈의 음료는 적정한 가격으로 결정되어야 한다. 예를 들어 최근 커피프랜차이즈 음료 가격이 너무 높게 책정되어 있는 경우가 많다. 식사 가격보다 커피 가격이 높은 경우도 있다. 따라서
커피프랜차이즈 기업은 많은 고객이 구매할 수 있도록 적정한 가격으로 제시할 필요가 있다.

본 연구는 커피프랜차이즈 소비자를 대상으로 서비스 품질이 만족, 자기 효능감, 그리고 충성도에 어떠한 영향을 미치는지 실증적으로 분석하여 이에 대한 이론적 및 관리적 시사점을 제시하였음에도 불구하고 다음과 같은 한계점이 있다. 본 연구는 온라인 설문조사 전문기관의 패널을 대상으로 조사되었다. 이러한 조사는 연구의 일반화에 한계가 있다. 따라서 향후 연구에서는 커피프랜차이즈 매장 방문 고객에게 직접 조사하여 표본의 신뢰성을 높일 필요가 있다. 또한, 향후 연구에서는 경상도 지역, 전라도 지역, 충청도 지역, 그리고 강원도 지역과 같이 다른 지역에 대한 연구도 필요하다.

\section{References}

Arboretti, R., \& Bordignon, P. (2016). Consumer preferences in food packaging: CUB models and conjoint analysis. British Food Journal, 118(3), 527-540.

Baker, J., Parasuraman, A., Grewal, D., \& Voss, G. B. (2002). The influence of multiple store environment cues on perceived merchandise value and patronage intentions. Journal of Marketing, 66(2), 120-141.

Baloglu, S., \& Brinberg, D. (1997). Affective images of tourism destinations. Journal of Travel Research, 35(4), 11-15.

Becker, T. (2000). Consumer perception of fresh meat quality: A framework for analysis. British Food Journal, 102(3), 158-176.

Berné, C., Múgica, J. M., \& Yagüe, M. J. (2001). The effect of variety-seeking on customer retention in services. Journal of Retailing and Consumer Services, 8(6), 335-345.

Berry, L. L., Wall, E. A., \& Carbone, L. P. (2006). Service clues and customer assessment of the service experience: Lessons from marketing. The Academy of Management Perspectives, 20(2), 43-57.

Berry, L. L., Zeithaml, V. A., \& Parasuraman, A. (1990). Five imperatives for improving service quality. MIT Sloan Management Review, 31(4), 29-38.

Bigne, J. E., Sanchez, M. I., \& Sanchez, J. (2001). Tourism image, evaluation variables and after purchase behaviour: Interrelationship. Tourism Management, 22(6), 607-616.

Bitner, M. J. (1990). Evaluating service encounters: The effects of physical surroundings and employee responses. Journal of Marketing, 54(2), 69-82.

Bolton, R. N., \& Drew, J. H. (1991). A multistage model of customers' assessments of service quality and value. Journal of consumer Research, 17(4), 375-384.

Brady, M. K., \& Cronin Jr, J. J. (2001). Some new thoughts on conceptualizing perceived service quality: A hierarchical approach. Journal of Marketing, 65(3), 34-49.

Brady, M. K., \& Robertson, C. J. (2001). Searching for a consensus on the antecedent role of service quality and satisfaction: An exploratory cross-national study. Journal of Business Research, 51(1), 53-60.

Brown, S. P., Cron, W. L., \& Slocum Jr, J. W. (1998). Effects of 
trait competitiveness and perceived intraorganizational competition on salesperson goal setting and performance. Journal of Marketing, 62(4), 88-98.

Caruana, A., Money, A. H., \& Berthon, P. R. (2000). Service quality and satisfaction-the moderating role of value. European Journal of Marketing, 34(11/12), 1338-1353.

Chen, C. F. (2008). Investigating structural relationships between service quality, perceived value, satisfaction, and behavioral intentions for air passengers: Evidence from Taiwan. Transportation Research Part A: Policy and Practice, 42(4), 709-717.

Chen, C. F., \& Tsai, M. H. (2008). Perceived value, satisfaction, and loyalty of TV travel product shopping: Involvement as a moderator. Tourism Management, 29(6), 1166-1171.

Clark, M. A., \& Wood, R. C. (1999). Consumer loyalty in the restaurant industry: A preliminary exploration of the issues. British Food Journal, 101(4), 317-327.

Cronin, J. J., Brady, M. K., \& Hult, G. T. M. (2000). Assessing the effects of quality, value, and customer satisfaction on consumer behavioral intentions in service environments. Journal of Retailing, 76(2), 193-218.

Ford, R. C., \& Dickson, D. R. (2012). Enhancing customer selfefficacy in co-producing service experiences. Business Horizons, 55(2), 179-188.

Gist, M. E. (1987). Self-efficacy: Implications for organizational behavior and human resource management. Academy of Management Review, 12(3), 472-485.

Grönroos, C. (1984). A service quality model and its marketing implications. European Journal of Marketing, 18(4), 36-44.

Hallowell, R. (1996). The relationships of customer satisfaction, customer loyalty, and profitability: An empirical study. International Journal of Service Industry Management, 7(4), $27-42$.

Heung, V. C., \& Gu, T. (2012). Influence of restaurant atmospherics on patron satisfaction and behavioral intentions. International Journal of Hospitality Management, 31(4), 1167-1177.

Hildebrand, D. A., \& Betts, N. M. (2009). Assessment of stage of change, decisional balance, self-efficacy, and use of processes of change of low-income parents for increasing servings of fruits and vegetables to preschool-aged children. Journal of Nutrition Education and Behavior, 41(2), 110-119.

Holbrook, M. B. (2006). Consumption experience, customer value, and subjective personal introspection: An illustrative photographic essay. Journal of Business Research, 59(6), 714725 .

Hurley, R. F., \& Estelami, H. (1998). Alternative indexes for monitoring customer perceptions of service quality: A comparative evaluation in a retail context. Journal of the Academy of Marketing Science, 26(3), 209-221.

Hussain, A., Mkpojiogu, E. O., \& Yusof, M. M. (2016, August). The effect of proposed software products' features on the satisfaction and dissatisfaction of potential customers. In AIP Conference Proceedings (Vol. 1761, No. 1, p. 020052). AIP Publishing LLC.

Jang, Y. T., Chang, S. E., \& Chen, P. A. (2015). Exploring social networking sites for facilitating multi-channel retailing. Multimedia Tools and Applications, 74(1), 159-178.
Jones, T. O., \& Sasser, W. E. (1995). Why satisfied customers defect. Harvard Business Review, 73(6), 88-99.

Kelley, K., Hyde, J., \& Bruwer, J. (2015). US wine consumer preferences for bottle characteristics, back label extrinsic cues and wine composition. Asia Pacific Journal of Marketing and Logistics, 27(4), 516-534.

Kivela, J., Inbakaran, R., \& Reece, J. (1999). Consumer research in the restaurant environment, Part 1: A conceptual model of dining satisfaction and return patronage. International Journal of Contemporary Hospitality Management, 11(5), 205-222.

Korda, A. P., \& Snoj, B. (2007). Direct and indirect effects of perceived price on perceived value of mobile phones. In Annales des Télécommunications, 62(10), 967-989.

Kotler, P., Bowen, J. T., Makens, J., \& Baloglu, S. (2017). Marketing for hospitality and tourism $7^{\text {th }}$ ed., Essex, UK: Pearson.

Lai, W. T., \& Chen, C. F. (2011). Behavioral intentions of public transit passengers: The roles of service quality, perceived value, satisfaction and involvement. Transport Policy, 18(2), 318-325.

Lee, E. J. (2019, November 6). Over 14,000 coffee shops newly open in Korea a year, 1 out of 10 makes losses. Maeiil Business News Korea. Retrieved from https://pulsenews.co.kr/view.php?year=2019\&no=915109

Lee, H., Lee, Y., \& Yoo, D. (2000). The determinants of perceived service quality and its relationship with satisfaction. Journal of Services Marketing, 14(3), 217-231.

Lee, W., \& Lambert, C. U. (2000). Impact of waiting time on evaluation of service quality and customer satisfaction in foodservice operations. Journal of Foodservice, 12(4), 241254.

Limayem, M., Hirt, S. G., \& Cheung, C. M. (2007). How habit limits the predictive power of intention: The case of information systems continuance. MIS Quarterly, 31(4), 705737.

Liu, Y., \& Jang, S. S. (2009). Perceptions of Chinese restaurants in the US: What affects customer satisfaction and behavioral intentions? International Journal of Hospitality Management, 28(3), 338-348.

Lu, H., \& Feng, Y. (2009). A measure of authors' centrality in coauthorship networks based on the distribution of collaborative relationships. Scientometrics, 81(2), 499-511.

Mahon, D., \& Cowan, C. (2004). Irish consumers' perception of food safety risk in minced beef. British Food Journal, 106(4), 301-312.

Mattila, A. S. (2001). Emotional bonding and restaurant loyalty. The Cornell Hotel and Restaurant Administration Quarterly, 42(6), 73-79.

McKee, D., Simmers, C. S., \& Licata, J. (2006). Customer selfefficacy and response to service. Journal of Service Research, 8(3), 207-220.

Méndez, J. L., Oubina, J., \& Rubio, N. (2011). The relative importance of brand-packaging, price and taste in affecting brand preferences. British Food Journal, 113(10), 1229-1251.

Moon, S. J., Costello, J. P., \& Koo, D. M. (2017). The impact of consumer confusion from eco-labels on negative WOM, distrust, and dissatisfaction. International Journal of Advertising, 36(2), 246-271. 
Namkung, Y., \& Jang, S. (2007). Does food quality really matter in restaurants? Its impact on customer satisfaction and behavioral intentions. Journal of Hospitality \& Tourism Research, 31(3), 387-409.

Nikolich, M. A., \& Sparks, B. A. (1995). The hospitality service encounter: The role of communication. Hospitality Research Journal, 19(2), 43-56.

Oliver, R. L. (1981). Measurement and evaluation of satisfaction processes in retail settings. Journal of Retailing, 57(3), 25-48.

Oliver, R. L. (1993). Cognitive, affective, and attribute bases of the satisfaction response. Journal of Consumer Research, 20(3), 418-430.

Olsen, M. D., \& Connolly, D. J. (2000). Experience-based travel: How technology is changing the hospitality industry. Cornell Hotel and Restaurant Administration Quarterly, 41(1), 30-40.

Ozer, E. M., \& Bandura, A. (1990). Mechanisms governing empowerment effects: A self-efficacy analysis. Journal of Personality and Social Psychology, 58(3), 472-486.

Parasuraman, A., Zeithaml, V. A., \& Berry, L. L. (1985). A conceptual model of service quality and its implications for future research. Journal of Marketing, 49(4), 41-50.

Parasuraman, A., Zeithaml, V. A., \& Berry, L. L. (1988). SERVQUAL: A multiple-item scale for measuring consumer perceptions of service quality. Journal of Retailing, 64(1), 1240.

Park, M. (2019, July 15). Domestic coffee industry nears 7 bln won as demand for premium coffee soars. The Korea Bizwire. Retrieved from http://koreabizwire.com/domestic-coffeeindustry-nears-7-billion-won-as-demand-for-premium-coffeesoars/140671

Petrick, J. F., \& Backman, S. J. (2002). An examination of the determinants of golf travelers' satisfaction. Journal of Travel Research, 40(3), 252-258.

Pine, B. J., \& Gilmore, J. H. (1998). Welcome to the experience economy. Harvard Business Review, 76, 97-105.

Raajpoot, N. A. (2002). TANGSERV: A multiple item scale for measuring tangible quality in food service industry. Journal of Foodservice Business Research, 5(2), 109-127.

Rai, A. K., \& Srivastava, M. (2012). Customer loyalty attributes: A perspective. NMIMS Management Review, 22(3), 49-76.

Russell, J. A., \& Pratt, G. (1980). A description of the affective quality attributed to environments. Journal of Personality and Social Psychology, 38(2), 311-322.

Rust, R. T., \& Oliver, R. L. (Eds.). (1993). Service quality: New directions in theory and practice. Thousand Oaks, C.A.: Sage Publications.

Ryu, K., Lee, H. R., \& Kim, W. G. (2012). The influence of the quality of the physical environment, food, and service on restaurant image, customer perceived value, customer satisfaction, and behavioral intentions. International Journal of Contemporary Hospitality Management, 24(2), 200-223.
Sharma, N., \& Patterson, P. G. (1999). The impact of communication effectiveness and service quality on relationship commitment in consumer, professional services. Journal of Services Marketing, 13(2), 151-170.

Shin, C. S., Hwang, G. S., Lee, H. W., \& Cho, S. R. (2015). The impact of Korean franchise coffee shop service quality and atmosphere on customer satisfaction and loyalty. The Journal of Business, Economics, and Environmental Studies (JBEES), 5(4), 45-57.

Silayoi, P., \& Speece, M. (2004). Packaging and purchase decisions: An exploratory study on the impact of involvement level and time pressure. British Food Journal, 106(8), 607-628.

Strieter, J. C., Celuch, K. G., \& Kasouf, C. J. (1999). Market oriented behaviors within organizations: An individual-level perspective. Journal of Marketing Theory and Practice, 7(2), 16-27.

Sulek, J. M., \& Hensley, R. L. (2004). The relative importance of food, atmosphere, and fairness of wait: The case of a fullservice restaurant. Cornell Hotel and Restaurant Administration Quarterly, 45(3), 235-247.

Sumaedi, S., Mahatma Yuda Bakti, G., \& Metasari, N. (2012). An empirical study of state university students' perceived service quality. Quality Assurance in Education, 20(2), 164-183.

Susanty, A., \& Kenny, E. (2015). The relationship between brand equity, customer satisfaction, and brand loyalty on coffee shop: Study of Excelso and Starbucks. ASEAN Marketing Journal, $7(1), 14-27$.

Susskind, A. M., \& Chan, E. K. (2000). How restaurant features affect check averages: A study of the Toronto restaurant market. The Cornell Hotel and Restaurant Administration Quarterly, 41(6), 56-63.

Taylor, S. A., \& Baker, T. L. (1994). An assessment of the relationship between service quality and customer satisfaction in the formation of consumers' purchase intentions. Journal of Retailing, 70(2), 163-178.

Tombs, A., \& McColl-Kennedy, J. R. (2003). Social- servicescape conceptual model. Marketing Theory, 3(4), 447-475.

Turner, L. W., \& Reisinger, Y. (2003). Cross cultural behaviour in tourism: Concepts and analysis. Oxford, U. K: Butterworth Heinemann

Zeithaml, V. A., Berry, L. L., \& Parasuraman, A. (1988). Communication and control processes in the delivery of service quality. Journal of Marketing, 60(2), 35-48.

Zeithaml, V. A., Berry, L. L., \& Parasuraman, A. (1996). The behavioral consequences of service quality. Journal of Marketing, 60(2), 31-46.

Zhong, Y. Y. S., Busser, J., \& Baloglu, S. (2017). A model of memorable tourism experience: The effects on satisfaction, affective commitment, and storytelling. Tourism Analysis, 22(2), 201-217. 